\title{
DELETERIOUS FUNCTIONAL IMPACT OF ANEMIA ON ADOLESCENTS: A SURVEY STUDY
}

\section{KARTHIGA DEVI*, JOTHI PRIYA}

Department of Physiology, Saveetha Dental College and Hospital, Chennai, Tamil Nadu, India. Email: karthigadevig98@gmail.com

\author{
Received: 13 May 2016, Revised and Accepted: 24 May 2016
}

\section{ABSTRACT}

Objective: To access the physical work capacity and cognition of underprivileged anemic adolescent, hemoglobin (Hb) of subjects was assessed for the adolescence under 17-20 years of age by undergoing survey.

Methods: This is a cross-sectional study, conducted in students of 1st year of Saveetha Dental College. The general information about age, Hb level (Sahli's method), knowledge about anemia, status of menstruation, and regarding the consumption of various diet factors were recorded on a structured questionnaire. Due to feasibility and cost effectiveness, Hb estimation was done by Sahli's hemoglobinometer.

Results: Our study proved that now a days adolescence is not much more prone to anemia. And mostly $40 \%$ of adolescence were having mild anemia. This mild anemia can be improved by dietary intake and bioavailability of iron, nutritional supplementation of iron and folic acid (IFA) tablets, and fortification of edible dietary items with iron. This difference was statistically significant (Chi-square value 4.848, $<<0.001$ ).

Conclusion: The study was mainly done for adolescence awareness on anemia. Iron deficiency anemia occurs most frequently in adolescence because accelerated physical growth both in boys and girls and menstruation and dieting for fear of obesity in female teenagers. The prevalence of anemia necessitates pragmatic intervention to improve the dietary intake, nutritional supplement of IFA tablets.

Keywords: Adolescence, Dietary factors, Knowledge about anemia.

\section{INTRODUCTION}

Anemia (from the ancient Greek, anemia, meaning "lack of blood") is defined by a decrease in the total amount of hemoglobin $(\mathrm{Hb})$ or the number of red blood cells. Iron deficiency anemia is a form of anemia due to the lack of sufficient iron to form normal red blood cells. Iron deficiency anemia is typically caused by inadequate intake of iron, chronic blood loss, or a combination of both. It is the most common cause of anemia in the world [1]. Adolescence is the age group between 10 and 19 years as defined by the World Health Organization [2]. This age coincides with the period of peak growth for boys and girls [3]. Nutritional requirements are more during adolescence with comparatively with body size [4]. Adolescence is a crucial developmental period. In adolescent girls on a marginal diet, iron deficiency may be a routine consequence of growth and skeletal development. Further, low iron stores throughout childhood may contribute to a delayed menarche and impaired immune response [5].

The present study highlights the problem of anemia in college going, adolescents residing in the city. Therefore, it is important to identify the prevalence of anemia among adolescent including male population which can be corrected with cost-effective interventions. This will prevent illnesses and disability during the most productive age of life.

\section{METHODS}

This is a cross-sectional study, conducted in students of 1st year of Saveetha Dental College. The general information about age, Hb level (Sahli's method), knowledge about anemia, status of menstruation, and regarding the consumption of various diet factors were recorded on a structured questionnaire. Due to feasibility and cost-effectiveness, $\mathrm{Hb}$ estimation was done by Sahli's hemoglobinometer. For interpretation of anemia, $\mathrm{Hb} \%<8 \%$ is considered as severe anemia, 8.1-10.0 $\mathrm{g} \%$ was considered as moderate anemia, $\mathrm{Hb} \%$ from $10.1 \%$ to $11.4 \%$ is considered mild anemia, and $\mathrm{Hb} \%$ above $11.4 \mathrm{~g} \%$ is considered normal. It may be due to the very high prevalence of anemia in the study group. The data were obtained in a pre-designed pro forma, entered into an excel sheet and analyzed using Statistical Package.

\section{RESULTS}

???

\section{DISCUSSION}

Adolescence is a period of transition from childhood to adulthood. It is characterized by rapid physical, biological, and hormonal changes resulting in psycho-social, behavioral, and sexual maturation. Adolescence is a period of rapid growth, and this will lead to increased iron requirement. Failure to fulfill this iron requirement leads to iron deficiency anemia [6]. Nutritional anemia is a major preventable public health problem in both developing and under developed countries.

Table 1: Gender-wise distribution of adolescence in this study

\begin{tabular}{ll}
\hline Gender & Frequency (\%) \\
\hline Male & $45(45.0)$ \\
Female & $55(55.0)$ \\
Total & $100(100.0)$ \\
\hline
\end{tabular}

Table 2: Age-wise distribution of adolescence in study

\begin{tabular}{llll}
\hline Age (years) & Frequency & Valid percent & Percent \\
\hline $17-18$ & 38 & 38.0 & 38.0 \\
$18-19$ & 44 & 44.0 & 82.0 \\
$19-20$ & 18 & 18.0 & 100.0 \\
Total & 100 & 100.0 & \\
\hline
\end{tabular}

Table 3: Diet-wise distribution of adolescence in this study

\begin{tabular}{llll}
\hline Diet & Frequency & Valid percent & Cumulative percent \\
\hline Veg & 25 & 25.0 & 25.0 \\
Non-veg & 75 & 75.0 & 100.0 \\
Total & 100 & 100.0 & \\
\hline
\end{tabular}


Table 4: Veg consumption of adolescence

\begin{tabular}{llll}
\hline Consumption & Frequency & $\begin{array}{l}\text { Valid } \\
\text { percent }\end{array}$ & $\begin{array}{l}\text { Cumulative } \\
\text { percent }\end{array}$ \\
\hline Weekly or less often & 35 & 35.0 & 35.0 \\
Weekly twice or thrice & 65 & 65.0 & 100.0 \\
Total & 100 & 100.0 & \\
\hline
\end{tabular}

Table 5: Non-veg consumption of adolescence

\begin{tabular}{llll}
\hline Consumption & Frequency & $\begin{array}{l}\text { Valid } \\
\text { percent }\end{array}$ & $\begin{array}{l}\text { Cumulative } \\
\text { percent }\end{array}$ \\
\hline No consumption & 24 & 24.0 & 24.0 \\
Weekly or less often & 43 & 43.0 & 67.0 \\
Weekly twice or thrice & 33 & 33.0 & 100.0 \\
Total & 100 & 100.0 & \\
\hline
\end{tabular}

Table 6: Hb distribution in adolescence of various age groups

\begin{tabular}{llllll}
\hline Gender & $<\mathbf{8}(\%)$ & $\mathbf{8 . 1 - 1 0}(\%)$ & $\mathbf{1 0 - 1 1 . 4}(\%)$ & $>\mathbf{1 1 4 0}(\%)$ & Total \\
\hline Male & $4(8.9)$ & $13(28.9)$ & $28(44.4)$ & $8(17.8)$ & 45 \\
Female & $2(3.6)$ & $13(23.6)$ & $20(36.4)$ & $20(36.4)$ & 55 \\
Total & $6(6.0)$ & $26(26.9)$ & $40(40.0)$ & $28(28.0)$ & 100 \\
\hline
\end{tabular}

Hb: Hemoglobin

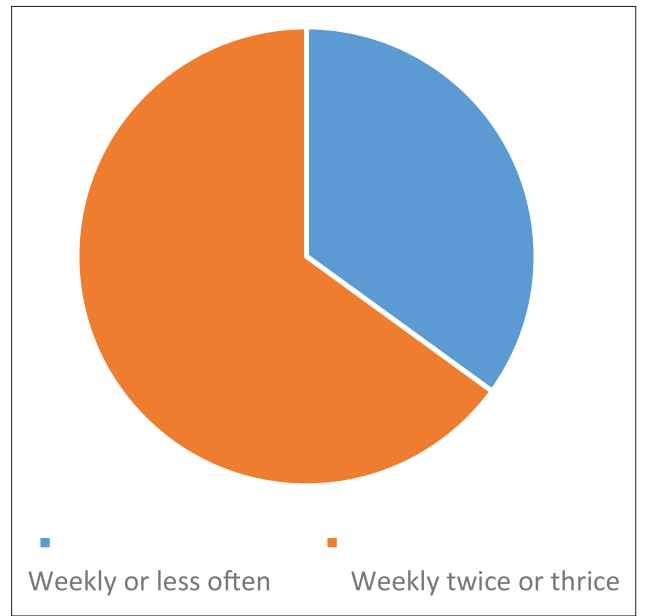

Fig. 1: Frequency of veg consumption among adolescence

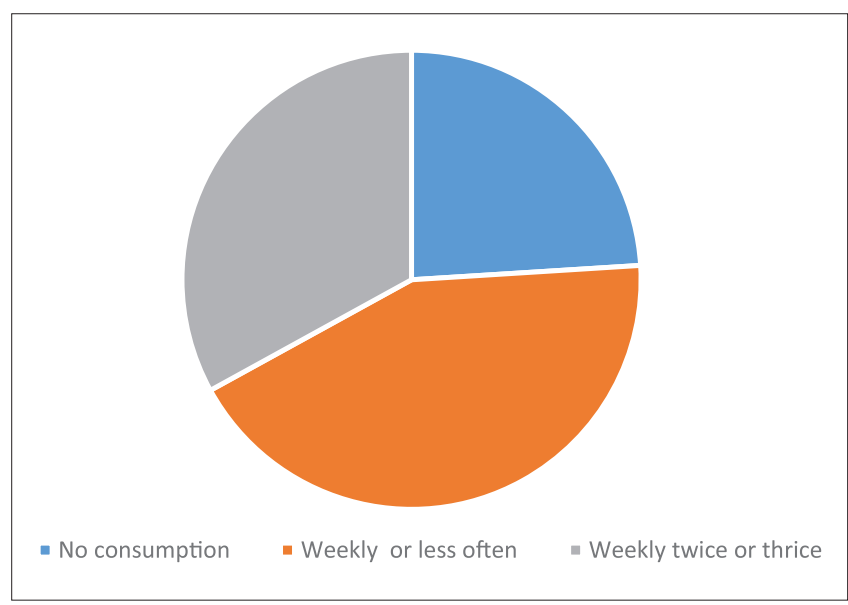

Fig. 2: Frequency of non-veg consumption among adolescence

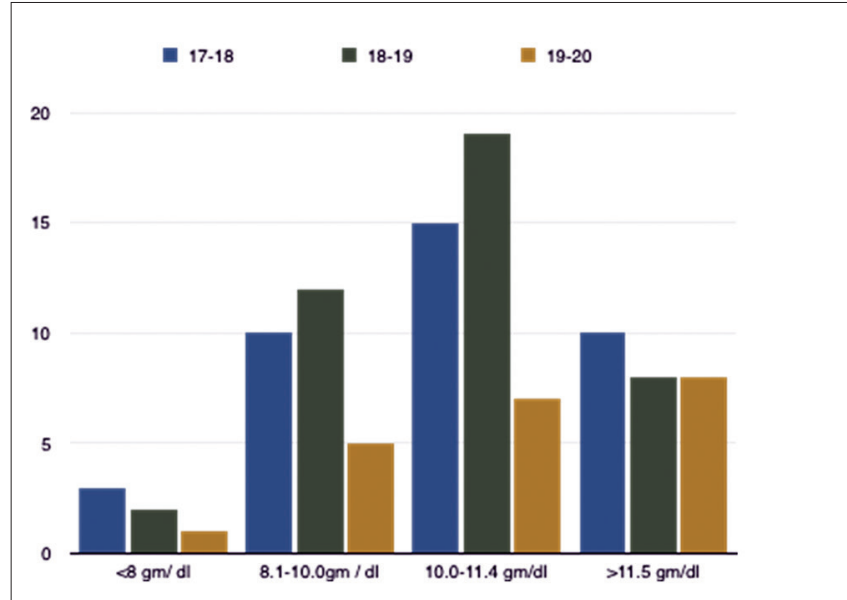

Fig. 3: Hemoglobin distribution in adolescence of various age groups

During adolescence, anemia is prevalent in both sexes, but more among girls, especially during menarche. Iron deficiency anemia among females is one of the major risk factors for infant mortality, maternal mortality, and preterm birth. It is becoming increasingly evident that the control of anemia in pregnant women can be more easily achieved if a satisfactory iron status can be ensured in the adolescent females before marriage. The reasons for the high incidence of anemia among adolescent girls include increased iron requirements because of growth, menstrual loss, discrepancy between high iron need for $\mathrm{Hb}$ formation and low intake of iron-containing foods, erratic eating habits, dislike for foods, which are rich in iron, like green leafy vegetables, iron absorption inhibitors in food (phytates/tannins) [7].

In our study, among 100 adolescence, $6.0 \%$ adolescence were anemic ( $45 \%$ males and $55 \%$ females). $\mathrm{Hb} \%<8 \%$ is considered as severe anemia, 8.1-10.0 g\% was considered as moderate anemia, $\mathrm{Hb} \%$ from $10.1 \%$ to $11.4 \%$ is considered mild anemia, $\mathrm{Hb} \%$ above $11.4 \mathrm{~g} \%$ is considered normal. In a total of 45 males, 8 were having (17.8\%) Hb above $11.4 \mathrm{~g} / \mathrm{dl}$ indicating normal. While 4 (8.9\%) having $\mathrm{Hb}$ levels ranging $<8 \mathrm{~g} / \mathrm{dl}$ indicating severe anemia, 13 (28.9\%) having Hb levels ranging from 8 to $10 \mathrm{~g} / \mathrm{dl}$ indicating moderate anemia, and 20 (44.4\%) had $\mathrm{Hb}$ levels ranging from 10.1 to $11.4 \mathrm{~g} / \mathrm{dl}$ indicating mild anemia. In a total of 55 females, 20 were having (36.4\%) Hb above $11.4 \mathrm{~g} / \mathrm{dl}$ indicating normal. While 2 (3.6\%) having Hb levels $<8 \mathrm{~g} / \mathrm{dl}$ indicating severe anemia, $13(23.6 \%)$ having hemoglobin levels ranging from 8 to $10 \mathrm{~g} / \mathrm{dl}$ moderate anemia, and 20 (36.4\%) had hemoglobin levels ranging from 10.1 to $11.4 \mathrm{~g} / \mathrm{dl}$ indicating mild anemia. From this study, males are anemia when compared to females, and hence, our study proved that now a days adolescence is not much more prone to anemia. And mostly $40 \%$ of adolescence were having mild anemia. This mild anemia can be improved by dietary intake and bioavailability of iron, nutritional supplementation of iron and folic acid (IFA) tablets, and fortification of edible dietary items with iron. This difference was statistically significant (Chi-square value 4.848, $\mathrm{p}<0.001$ ). The association of anemia and body mass index as seen in the present study is also well-established [8]. Other than these, questionnaire, which contains tea or coffee consumption, stress factor, and menstrual bleeding for girls, was also mentioned.

\section{CONCLUSION}

The study was mainly done for adolescence awareness on anemia. Iron deficiency anemia occurs most frequently in adolescence because accelerated physical growth both in boys and girls and menstruation and dieting for fear of obesity in female teenagers. The prevalence of 
anemia necessitates pragmatic intervention to improve the dietary intake, nutritional supplement of IFA tablets.

\section{REFERENCES}

1. Clark SF. Iron deficiency anemia: diagnosis and management. Curr Opin Gastroenterol 2009;25(2):122-8.

2. Programming for adolescent health and development. Report of a WHO/UNFPA/UNICEF Study Group on Programming for Adolescent Health. World Health Organ Tech Rep Ser 1999;886:i-vi, 1-260.

3. Tanner JM. Growth of Adolescents. 2nd ed. Oxford: Blackwell Scientific Publication; 1962. p. 326-41.

4. Pushpamma P, Geervani P, Devi NL. Food intake, nutrient adequacy and anthropometry of adolescents in Andhra Pradesh. Indian J Med Res
$1982 ; 75: 61-7$

5. Brabin L, Brabin BJ. The cost of successful adolescent growth and development in girls in relation to iron and vitamin A status. Am J Clin Nutr 1992;55(5):955-8.

6. The adolescent girls anaemia control programme breaking the intergenerational cycle of under nutrition in india with a focus on adolescent girls. The United Nations Children's Fund. New Delhi, 2011. Available from: http://www. unicef.org/india/14._Adolescent_Anaemia_Control_ Programme.pdf. [Last Cited on 2014 Oct 28].

7. Shekhar A. The iron status of adolescent girls and its effect on their physical fitness. Indian J Nutr Diet 2005;42(10):451-45.

8. Gopalan C, Ramasastri BV, Balasubramaniam SC. Nutritive Value of Indian Foods. Hyderabad: National Institute of Nutrition Press, ICMR; 1993. p. $47-58$

Author Queries???

AQ1: Kindly provide text part

AQ2: Kindly cite tables 1-6 in text part

AQ3: Kindly provide column head

AQ4: Kindly provide significant value

AQ5: Kindly cite figures 1-3 in text part 